\title{
Transferring patients for primary angioplasty: a retrospective analysis of 104 selected high risk patients with acute myocardial infarction
}

Felix Zijlstra, Arnoud W J van't Hof, Ay Lee Liem, Jan C A Hoorntje, Harry Suryapranata, Menko-Jan de Boer

\begin{abstract}
Objective-To investigate the feasibility of primary coronary angioplasty as a treatment option in patients with acute myocardial infarction after initial diagnosis in a local community hospital.

Setting-Referral centre for interventional treatment of coronary artery disease.

Methods-During a five year period, 520 candidates for primary coronary angioplasty were treated in our institution, 104 after transfer from a community hospital. The transferred patients and the nontransferred patients $(n=416)$ were compared with regard to baseline clinical characteristics, time interval from symptom onset to treatment, and clinical outcome at six months.

Results-In this setting, the influence of transportation on total ischaemic time was limited, and there was no difference in clinical outcome between the transferred and the non-transferred patients. Clinical outcome was mainly dependent on the indication for transfer.

Conclusions-Safe and expedient transportation may facilitate the more widespread use of primary angioplasty in patients with acute myocardial infarction. A large randomised multicentre trial is needed to compare the relative merits of intravenous thrombolytic treatment in a local hospital with primary angioplasty after transfer in selected high risk patients with acute myocardial infarction. (Heart 1997;78:333-336)
\end{abstract}

Keywords: myocardial infarction; coronary angioplasty; reperfusion

Several randomised trials have recently shown that primary coronary angioplasty - defined as angioplasty performed on the infarct related vessel - during the early hours of acute myocardial infarction, without the use of thrombolytic agents, offers certain advantages over intravenous thrombolytic treatment. ${ }^{1-4}$ Rapid and sustained patency of the infarct related vessel is obtained in most patients, resulting in a lower mortality and less reinfarction without exposing them to the bleeding risks associated with thrombolytic treatment. ${ }^{5}$ The major limitation of primary angioplasty as first line treatment of acute myocardial infarction is its restricted availability. Even in Europe and North America, most hospitals do not have facilities for coronary angioplasty. For patients admitted to a hospital without angioplasty facilities this implies transportation to a hospital with interventional cardiology services. The time loss and the risks associated with transportation might negate (part of) the benefits of primary angioplasty compared to thrombolytic treatment. To compare intravenous thrombolytic treatment in a local facility with primary coronary angioplasty after transportation to a referral centre for interventional treatment of coronary artery disease, a multicentre randomised trial is currently planned in The Netherlands. This trial will enrol selected high risk patients with acute myocardial infarction with a substantial risk of adverse clinical events.

To investigate the feasibility, safety, and logistic implications of the emergency transport of these categories of patients we performed a retrospective analysis of all patients who underwent such a procedure in our institution. To put the clinical outcome of these transferred patients into perspective, we made a comparison with the primary angioplasty patients admitted directly to our hospital, although it is clear that the baseline characteristics of these two groups of patients are different. However, at present more appropriate data for comparison are not available.

\section{Methods}

The Weezenlanden Hospital is a referral centre for interventional treatment of cardiac diseases. Four interventional cardiologists perform 1600 coronary angioplasties per year and four thoracic surgeons perform 1400 cardiac surgical procedures per year. In our referral area, we and 14 other hospitals serve a population of 1.4 million. Transportation from most referral hospitals to our hospital is possible within 40 minutes, as the ambulance services are well organised and cooperative, and are used to working in close collaboration with coronary care units and catheterisation laboratories. Transportation of patients for elective and urgent coronary angioplasty procedures for stable and unstable angina is daily routine. Traffic congestion is rare in our part of The Netherlands. During the night and weekend an interventional cardiologist and catheterisation staff are on call. There are two catheterisation laboratories. There is 24 hour surgical back up. When a telephone call is received from a refer- 
Table 1 Baseline characteristics and initial treatment

\begin{tabular}{llll}
\hline & $\begin{array}{l}\text { Non-transferred } \\
(n=416)\end{array}$ & $p$ & $\begin{array}{l}\text { Transferred } \\
(n=104)\end{array}$ \\
\hline Age (years; mean (SD)) & $61(11)$ & NS & $59(11)$ \\
Male (\%) & 78 & NS & 77 \\
Previous MI (\%) & 19 & $<0.001$ & 22 \\
Anterior MI (\%) & 42 & $<0.05$ & 12 \\
Killip class 3 or 4 (\%) & 6 & $<0.001$ & 31 \\
CI for thrombolysis (\%) & 13 & NS & 59 \\
Multivessel disease (\%) & 60 & & \\
Initial treatment & & NS & 98 \\
$\quad$ Primary angioplasty (\%) & 93 & NS & 1 \\
$\quad$ Conservative approach (\%) & 4 & NS & 1 \\
$\quad$ Emergency CABG (\%) & 3 & artery byps & grafting. \\
\hline
\end{tabular}

MI, myocardial infarction; CI, contraindication; CABG, coronary artery bypass grafting.

ring physician during the daily programme, it is always possible to have one of the two rooms prepared the moment the patient arrives in our hospital. The transported patients are accompanied by well trained paramedics from the ambulance services. In cases of marked haemodynamic or electrical instability, a physician from the referring hospital travels with the patient.

\section{PATIENTS}

Between August 1990 and April 1995, 729 patients with symptoms of acute myocardial infarction and ST segment elevation on at least two contiguous electrocardiographic leads presented to or were referred to our institution. Of the patients who presented directly to our hospital, $87 \%$ participated in one of our trials. ${ }^{1246}$ Thrombolytic treatment was given to 205 patients and 520 were candidates for primary angioplasty. Of these 520 patients, 416 presented directly to our hospital, and 104 were initially admitted to another hospital without a catheterisation laboratory or angioplasty expertise and were transferred by ambulance for immediate angiography with a view to primary angioplasty after an initial diagnosis of acute myocardial infarction had been made at the local facility. When the decision to transfer was made, the patient was included in this analysis, irrespective of whether primary angioplasty was actually performed. None of the transported patients participated in one of our reported trials, ${ }^{1246}$ as the decision to go for primary angioplasty had already been made and communicated to the patient as well as to relatives by the referring physician. Transferred patients were directed immediately towards the cardiac catheterisation laboratory to avoid additional delay resulting from a second assessment in an emergency room or coronary care unit.

\section{Indications for transfer}

In all the 14 hospitals that transferred these patients, thrombolysis is the first choice reperfusion treatment for acute myocardial infarction. Predefined indications for transfer for primary coronary angioplasty were: contraindications to thrombolytic treatment, with electrocardiographic evidence of a large myocardial territory at risk (31\%); Killip class 3 or $4(14 \%)$; and anterior wall infarctions with $2 \mathrm{mV}$ cumulative ST segment elevation (67\%).
MAIN OUTCOME MEASURES

Time of symptom onset, times of hospital admission, and transfer time, defined as time between first and second hospital admission, were recorded. Clinical end points, defined as previously described, ${ }^{1}$ and additional revascularisation procedures were assessed at six months to compare the transferred and the non-transferred patients.

STATISTICS

Data are expressed as mean (SD). Categorical data were analysed by Fisher's exact test or the $\chi^{2}$ test. Continuous variables were analysed by the unpaired Student $t$ test. A p value of $<0.05$ was considered statistically significant.

\section{Results}

INITIAL TREATMENT AND CLINICAL CHARACTERISTICS

One patient with cardiogenic shock died during transportation and one patient in the non-transferred group died in the emergency room shortly after admission. Coronary angiography was performed in all other patients $(n=518)$. Primary angioplasty was performed in 486 patients (94\%) with a procedural success rate, defined as previously described, ${ }^{4}$ of $97 \%$. A conservative approach was followed in 23 patients $(4.4 \%)$ and nine patients $(1.7 \%)$ had emergency coronary artery bypass grafting without an attempt at angioplasty. Baseline characteristics of the two patient groups are shown in table 1 . Complications in the transferred patients during coronary angiography and angioplasty occurred in 15 cases $(14.4 \%)$. Two patients died during the procedure in cardiogenic shock, despite extensive resuscitation efforts. Six patients needed defibrillation and one needed a temporary pacemaker for third degree atrioventricular block. Major dissections occurred in five patients and were managed by bail-out stenting (three patients) or, in the presence of severe triple vessel disease, by coronary artery bypass grafting (two patients). Two patients had allergic skin reactions and hypertension probably due to the contrast agent. In the transferred patients, hospital mortality was $6.7 \%$, inhospital reinfarction occurred in $2.9 \%$ of patients, and additional revascularisation procedures were performed in $17.3 \%$. Four patients underwent a second angioplasty procedure-in two of them because of signs of reocclusion-and 14 patients had coronary artery bypass grafting for triple vessel or left main disease.

TRANSPORTATION AND TIME DELAYS One patient died during transportation (1\%). This patient was already in profound cardiogenic shock before being transported. During

Table 2 Time between symptom onset and first balloon inflation

\begin{tabular}{llc}
\hline Hours & Non-transferred (\%) & Transferred (\%) \\
\hline $0-2$ & 11 & 6 \\
$2-4$ & 52 & 52 \\
$4-6$ & 22 & 20 \\
$>6$ & 15 & 22 \\
\hline
\end{tabular}


Table 3 Time delays of patients treated within six hours

\begin{tabular}{lcc}
\hline & $\begin{array}{l}\text { Non-transferred } \\
(n=416)\end{array}$ & $\begin{array}{c}\text { Transferred } \\
(n=104)\end{array}$ \\
\hline $\begin{array}{l}\text { Symptom onset to hospital admission } \\
\text { Admission local community hospital-admission WZL }\end{array}$ & $129(69)$ & $91(60)$ \\
$\begin{array}{l}\text { Admission WZL-first balloon inflation of primary } \\
\quad \text { coronary angioplasty procedure }\end{array}$ & $67(28)$ & $39(27)$ \\
Total ischaemia time & $196(74)$ & $200(62)$ \\
\hline
\end{tabular}

All times are in minutes (SD); WZL, hospital De Weezenlanden.

transportation 10 patients $(9.6 \%)$ were in cardiogenic shock. All were on inotropic support. One patient needed mechanical ventilation before transportation, and one additional patient was intubated during transport. In addition to the 14 patients who were in Killip class 3 or 4 before transportation, two patients required treatment for hypotension (fluid expansion and intravenous dobutamine). Ventricular tachycardia occurred in one patient and was treated with intravenous lignocaine. Two patients were defibrillated for ventricular fibrillation during transportation. No other adverse events occurred during or as a result of transportation. Travel distances of the transferred patients were $<25 \mathrm{~km}$ in $61 \%$, between 25 and $50 \mathrm{~km}$ in $30 \%$, and $>50 \mathrm{~km}$ in $9 \%$. The time from symptom onset to first balloon inflation in the two groups of patients is shown in table 2. As patient delay ${ }^{7}$ is the predominant determinant of time to treatment in patients treated after six hours, the detailed analysis of time delays shown in table 3 is restricted to patients treated within six hours. Differences in baseline characteristics (table 1) may be responsible for the shorter time from symptom onset to initial hospital presentation of the transferred patients (table 3), as sicker patients tend to call for help earlier after symptom onset. An additional 28 minutes is gained back from the time lost during transfer by rapid in-hospital transfer to the catheterisation laboratory. As a result of these differences, the time delay between first and second hospital admission is not reflected in the comparable total ischaemic periods of 196 and 200 minutes in the two groups of patients, as shown in table 3 .

\section{CLINICAL OUTCOME}

Clinical outcome at six months is shown in table 4 . The high percentage of patients in the transferred group with baseline characteristics known to be associated with a higher risk of untoward events ${ }^{8-10}$ results in a somewhat higher incidence of revascularisation procedures, non-fatal recurrent infarction, and death, although none of these differences reached statistical significance.

Table 4 Clinical outcome at six months

\begin{tabular}{llll}
\hline & $\begin{array}{c}\text { Non-transferred } \\
(\%)(n=416)\end{array}$ & $p$ & $\begin{array}{l}\text { Transferred } \\
(\%)(n=104)\end{array}$ \\
\hline Re-PTCA & 12.5 & NS & 12.5 \\
CABG & 13.7 & NS & 17.3 \\
Re-MI & 2.6 & NS & 3.8 \\
Death & 6.7 & NS & 8.7 \\
\hline
\end{tabular}

Re-PTCA, repeated percutaneous transluminal coronary angioplasty; CABG, coronary artery bypass grafting; Re-MI, recurrent myocardial infarction.

\section{Discussion}

Outcome after myocardial infarction can be improved by prompt reperfusion of the infarct related coronary artery. Primary coronary angioplasty and thrombolysis are complementary methods of reperfusion treatment and both strategies are still evolving. Angioplasty equipment and technique (stents?), improved dosing regimens and new drugs for thrombolysis, and improved adjunctive treatment such as antithrombin and antiplatelet agents for both types of treatment are ongoing developments that can be expected to improve outcome further, and will influence the balance between these methods of treatment, along with economic and logistic issues. Emerging data support a role for primary coronary angioplasty, where it is available and accessible, but the extent and limitations of this role require further clarification. ${ }^{11-18}$ At this moment the large majority of patients with an acute myocardial infarct is admitted to hospitals without a catheterisation laboratory or angioplasty expertise, even in Europe and North America. This means that additional transportation, with inherent risks and time delay, will be necessary for many patients if a strategy of primary coronary angioplasty is introduced into clinical practice.

Several trials are currently being prepared to compare optimal thrombolytic treatment at a local hospital, or even prehospital thrombolysis, with primary coronary angioplasty after transfer to a hospital with interventional cardiology. Although not yet based on evidence from randomised trials, transfer of selected patients may be appropriate if the benefits of primary angioplasty are likely to outweigh the risk of transportation and the negative impact of the additional time delay. Patients with contraindications for thrombolytic treatment and a large myocardial territory at risk, patients with extensive anterior wall infarctions, and those with clear evidence of haemodynamic instability during the early hours of infarction may benefit from this approach. Emergency interhospital transport of patients during the early hours of acute myocardial infarction has been described as feasible and safe.[19 20] However, in these previous reports patients usually had thrombolytic treatment before transportation to a tertiary facility for coronary angiography. Mortality and morbidity during transportation were low but the additional time delay averaged more than two hours, resulting in arrival in the catheterisation laboratory around six hours after symptom onset. In particular, if myocardial salvage is one of the goals of the therapeutic strategy then the time to reperfusion is crucial. In contrast with these previous reports, ${ }^{19}{ }^{20}$ in our setting a large proportion of patients is treated within the time frame that makes myocardial salvage possible, as $58 \%$ of transferred patients had a first balloon inflation within four hours and $78 \%$ within six hours after symptom onset. As primary coronary angioplasty results in a patency rate-defined as TIMI 3 flow $^{4}$ - of more than $90 \%$, in theory this would be better than thrombolytic treatment at a local facility, ${ }^{21}$ in particular if less than one hour is lost in 
transfer. This is a strong argument in favour of a large multicentre study.

LIMITATIONS

It should be recognised that the transferred patients were selected for this treatment by the referring physicians on the basis of limited available information, usually consisting of a (short) history, the most pertinent findings from physical examination, and a 12 lead electrocardiogram. Although no patients were transferred who did not fulfil one of our predefined indications, we do not know how many patients who fulfilled these criteria were not transferred, as we have no systematic data concerning all hospital admissions with myocardial infarction in the referring hospitals. In particular, we do not know how many patients were deemed too sick to transfer, although personal communication from the referring physicians suggests that this is rare. Although some referring hospitals have portable intra-aortic balloon pumps, they are used very seldom for this indication, as the additional delay resulting from the insertion procedure before transportation offsets the advantage of this support device.

CONCLUSIONS AND CLINICAL IMPLICATIONS

Our data show that, at least in certain circumstances, primary coronary angioplasty after transportation to a referral centre for interventional treatment of cardiac disease can be used in patients initially admitted to a hospital without angioplasty facilities. The risk of death due to transportation is low and the effect on total ischaemic time (time from symptom onset to balloon inflation) is small. A large randomised multicentre trial is needed to compare the relative merits of intravenous thrombolytic treatment in a local hospital with primary angioplasty after transfer in selected high risk patients with acute myocardial infarction.

1 Zijlstra F, de Boer MJ, Hoorntje JCA, Reiffers S, Reiber JHC, Suryapranata H. A comparison of immediate coronary angioplasty with intravenous streptokinase in acute myocardial infarction. N Engl F Med 1993;328:680-4.
2 De Boer MJ, Suryapranata H, Hoorntje JCA, Reiffers S, Liem AL, Miedema K, et al. Limitation of infarct size and preservation of left ventricular function after primary preservation of left ventricular function after primary coronary angioplasty compared with intravenous streptokinase in

3 Grines CL, Browne KF, Marco J, Rothbaum D, Stone GW, O'Keefe J, et al, for the Primary Angioplasty in Myocardial Infarction Study group. A comparison of immediate angioplasty with thrombolytic therapy for acute myocardial infarction. N Engl f Med 1993;328:673-9.

4 De Boer MJ, Reiber JHC, Suryapranata $\mathrm{H}$, van den Brand MJBM, Hoorntje JCA, Zijlstra F. Angiographic findings and catheterization laboratory events in patients with primary coronary angioplasty or streptokinase therapy for primary coronary angioplasty or streptokinase therapy for

acute myocardial infarction. Eur Heart f 1995;16:1347-55. Gore JM, Granger CB, Simoons ML, Sloan MA, Weaver WD, White $\mathrm{HD}$, et al. Stroke after thrombolysis. Mortality and functional outco

6 Zijlstra F, Beukema WP, Liem AL, Suryapranata H, Hoorntje JCA, de Boer MJ. Results of the pilot phase of an ongoing randomized trial to evaluate a strategy of primary angioplasty for high risk and thrombolysis for low risk patients with acute myocardial infarction [abstract]. Circulation 1994;90:I-168.

7 GISSI. Epidemiology of avoidable delay in the care of patients with acute myocardial infarction in Italy. Arch Intern Med 1995;155:1481-8.

8 Hillis LD, Forman S, Braunwald E and the TIMI phase 2 Co-investigators. Risk stratification before thrombolytic therapy in patients with acute myocardial infarction. $7 \mathrm{Am}$ Coll Cardiol 1990;16:313-15.

9 Brodie BR, Weintraub RA, Stuckey TD, Le Bauer EJ, Katz JD, Kelly TA. Outcomes of direct coronary angioplasty for acute myocardial infarction in candidates and noncandidates for thrombolytic therapy. Am f Cardiol 1991;67: $7-12$.

10 Simoons ML, Arnold AER. Tailored thrombolytic therapy. A perspective. Circulation 1993;88:2556-64

11 Kligfield P. Primary angioplasty in myocardial infarction. $\mathrm{Br}$ Heart f 1 1995;73:403.

12 Zijlstra F. Primary angioplasty: the most effective therapy for patients with an acute myocardial infarction. Br Heart $\mathcal{F}$ 1995;73:403-4

13 Grines CL, O’Neill WW. Primary angioplasty. Br Heart $\mathcal{f}$ 1995;73:405-6.

14 De Jaegere PP, Simoons ML. Immediate angioplasy: a conservative view from Europe. Br Heart f 1995;73:407-8.

15 Vaitkus PT. Limitations of primary angioplasty in acute myocardial infarction. Br Heart f 1995;73:409-10.

16 Brodie BR. Primary angioplasty in a community hospital in the USA. Br Heart $\mathcal{F}$ 1995;73:411-12.

17 Boyle RM. Immediate angioplasty in the United Kingdom. Br Heart f 1995; 73:413-14.

18 Ramsdale DR, Grech ED. Experience of primary angioplasty in the United Kingdom. Br Heart f 1995;73:414-
of 16.

19 Bellinger RL, Califf RM, Mark DB, Weber RA, Collins P, Stone J, et al. Helicopter transport of patients during acute myocardial infarction. Am $\mathcal{F}$ Cardiol 1988;61:718-22.

20 Gore JM, Corrao JM, Goldberg RJ, Ball SP, Weiner BH, Aghababian RV, et al. Feasibility and safety of emergency interhospital transport of patients during early hours of acute myocardial infarction. Arch Intern Med 1989;149: 353-5.

21 GUSTO Angiographic Investigators. The effects of tissue plasminogen activator, streptokinase or both on coronary artery patency, ventricular function, and survival after acute myocardial infarction. N Engl F Med 1993;329:1615-22. 